\title{
Resistance to satiation as a function of three satiation procedures
}

\author{
ELIZABETH D. CAPALDI and DAVID E. MYERS \\ Purdue University, West Lafayette, Indiana 47907
}

\begin{abstract}
Three groups of rats were trained to run a straight alley while hungry and tested while satiated. Group C was satiated only with lab chow, Group M with lab chow and wet mash, and Group P with lab chow and Noyes pellets. In satiated testing Group P ran significantly slower than Group $\mathrm{C}$ and ate fewer pellets in the alley than either group $\mathrm{C}$ or $\mathrm{M}$. These results are consistent with an associative interpretation that assumes that resistance to satiation of eating and running is greater the higher the proportion of cues present in satiated testing that had been conditioned in acquisition.
\end{abstract}

There has been a growing interest in the phenomenon of resistance to satiation, that is, the tendency during satiated testing for continued performance of behaviors that had been learned under hunger. In a simple instrumental learning task that measures running in a straight alley, this phenomenon is robust and has been shown to be a function of a number of different acquisition and testing variables, such as schedule of reward, reward magnitude, and the presence or absence of reward during satiated testing (e.g., Capaldi \& Myers, 1978).

One problem that has emerged in this area is the definition of satiation. There is no widely accepted definition of satiation available today, and in the past satiation has usually been operationally defined in terms of exposure to various types of food for some length of time preceding and during satiated testing. Some studies prefed animals for short periods of time (i.e., 30-90 $\mathrm{min}$ ) before each test session (Black \& Black, 1967; Cox, 1976; Pencer, 1974). Some studies allowed animals to consume ad-lib food for 1-2 days prior to and during satiated testing (Gragg \& Black, 1967; Haas, Shessel, Willner, \& Rescorla, 1970; Linton \& Miller, 1951), while others allowed ad-lib food consumption for longer periods of time prior to satiated testing, ranging from 10 days to 2 months (Black \& Cox, 1973; Capaldi \& Myers, 1978; Wong \& Traupmann, 1973a, 1973b, 1975). The type of food used to satiate animals in these studies has also varied. Most studies gave animals regular lab chow, while several studies supplemented (or used exclusively) reward pellets (Capaldi \& Myers, 1978; Pencer, 1974), wet mash mixtures (i.e., either ground chow and water or ground chow, milk, and sugar) (Black \& Black, 1967; Linton \& Miller, 1951), or both pellets and mash (Black \& Cox, 1973; Cox, 1976; Gragg \& Black, 1967; Haas et al., 1970). A few of these studies noted that animals did not

This research was supported in part by a Purdue Research Foundation David Ross grant. Reprint requests should be sent to Elizabeth D. Capaldi, Department of Psychological Sciences, Purdue University, West Lafayette, Indiana 47907. eat prior to running (Black \& Cox, 1973; Capaldi \& Myers, 1978). Only one study (Capaldi \& Myers, 1978) used body weight as an index of satiation, noting that body weight is the most widely accepted antecedent condition of hunger drive (Bolles, 1975; Weinstock, 1972).

It is clear that procedures for producing satiation are varied and there is no good indication from these studies of how differing methods affect resistance to satiation. An attempt was made here to systematically study the effect of three different types of food in the home cage on resistance to satiation of running and eating in a straight alley.

\section{METHOD}

\section{Subjects}

The subjects were 30 naive male rats, about 90 days old upon arrival from the Holtzman Company, Madison, Wisconsin.

\section{Apparatus}

The apparatus consisted of a runway painted a flat gray throughout, $144.8 \mathrm{~cm}$ long and $8.9 \mathrm{~cm}$ wide, with $10.2-\mathrm{cm}$-high sides and covered with $1.3-\mathrm{cm}$ hardware cloth. The $27-\mathrm{cm}-\mathrm{long}$ startbox was separated from the runway by a metal door that the experimenter dropped by pushing a button. Dropping the door started the first of three .01-sec Standard clocks. Clock 1 was stopped (start time) and Clock 2 started when the rat interrupted a photobeam $30.5 \mathrm{~cm}$ from the door. Clock 2 was stopped (run time) and Clock 3 started when the rat broke a second photobeam located $43.2 \mathrm{~cm}$ from the first. Interruption of a third photobeam stopped Clock 3 (goal time). The third photobeam was $30.5 \mathrm{~cm}$ beyond the second photobeam and $7.6 \mathrm{~cm}$ in front of a gray block of wood with a $1.9-\mathrm{cm}-$ deep $\times$ 3.17-cm-diam hole used as a food cup. A manually lowered guillotine door, $34.3 \mathrm{~cm}$ from the rear of the goal compartment, served to confine the subject to the goal area. Times from the three clocks were summed to obtain total time.

\section{Procedure}

The experiment was run by two experimenters, each running one-half of the subjects in each group. Six days following arrival to the laboratory (Day 1), the subjects were weighed and randomly assigned to three groups matched on weight. Deprivation began on Day 1. All rats received $13 \mathrm{~g}$ of food (Wayne Lab Blox) per day and were given ad-lib water. Each rat 
was handled individually on Days $1-10$, and on Days 9 and 10 , each rat was given a small dish containing two .045-g Noyes pellets before feeding. On Days 11 and 12, each rat received one pretraining trial rewarded with two .045 -g pellets; Phase 1 began the following day. On Days 1-16 of Phase 1 , rats were partially rewarded for three trials per day. Letting $R$ represent rewarded trials and $\mathrm{N}$ represent nonrewarded trials, all groups received RNR sequence on Days $1,4,7,10,13$, and 16 , NNR sequence on Days 2, 5, 8, 11, and 14, and NRR sequence on Days 3, 6, 9, 12 , and 15 . There was a break between Days 15 and 16 when animals were fed their daily rations but not run. Each day animals were run randomly within squads of three, composed of one subject from each group, producing an intertrial interval of 2-3 min. Animals were removed from the goalbox immediately after consuming their rewards, or after $20 \mathrm{sec}$ on nonrewarded trials. On every trial, $60 \mathrm{sec}$ were allowed in each section before a rat was guided to the next section and $60 \mathrm{sec}$ were recorded for the untraversed portion. Each squad was fed its daily ration $15 \mathrm{~min}$ following the last daily trial for that squad. On Day 16 rats were given ad-lib food after the last trial. Phase 2 began 18 days later, when all subjects had reached the level of their Day 1 weights and were stable. Two days prior to the start of Phase 2, and on each day of Phase 2, two of the groups were given dishes with either $24 \mathrm{~g}$ of .045 -g Noyes pellets (Group P) or approximately $85 \mathrm{~g}$ of wet mash (Group M) in addition to their lab chow. Mash was prepared daily by mixing 1.0 part ground lab chow and 1.5 parts water. Group $C$ was maintained on ad-lib lab chow. During Phase 2, $15 \mathrm{~min}$ prior to running, the dishes for Groups $\mathrm{P}$ and $\mathrm{M}$ were weighed and replenished with fresh pellets or mash, respectively. When being run in Phase 2, rats received a trial unless they were eating their respective foods, although in practice this rarely occurred. Phase 2 lasted for 12 days, during which animals received three trials per day rewarded with two pellets. The amount eaten on each trial was recorded and animals were removed from the goalbox after consuming the reward or after $20 \mathrm{sec}$, whichever came first. All other procedures were the same as in Phase 1.

\section{RESULTS}

All times were converted by logarithmic transformation $\left[\log _{10}(\sec +1)\right]^{1}$ and analyzed in a between/within analysis of variance. Group and experimenter were between-subjects factors and days and trials were withinsubjects factors. Since results were substantially the same in all alley sections, only total log times are presented. The experimenter variable did not interact with any other variables, so it is not mentioned further. For all analyses the .05 level of confidence was employed.

\section{Running Times}

During Phase 1, when groups were treated identically, running times decreased significantly over days $[F(15,360)=109.01]$, but groups did not differ significantly over all of the phase $[\mathrm{F}(2,24)=2.41, \mathrm{p}>.1]$, nor on the last day of Phase $1(\mathrm{~F}<1)$.

Figure 1 shows the mean total log times for each group on the last day of Phase 1 and each day of Phase 2. As can be seen in Figure 1, for all groups during Phase 2, running times increased immediately from their Phase 1 levels and gradually increased over Phase 2. Furthermore, the increase in running times during satiated testing was greatest for Group P and resistance

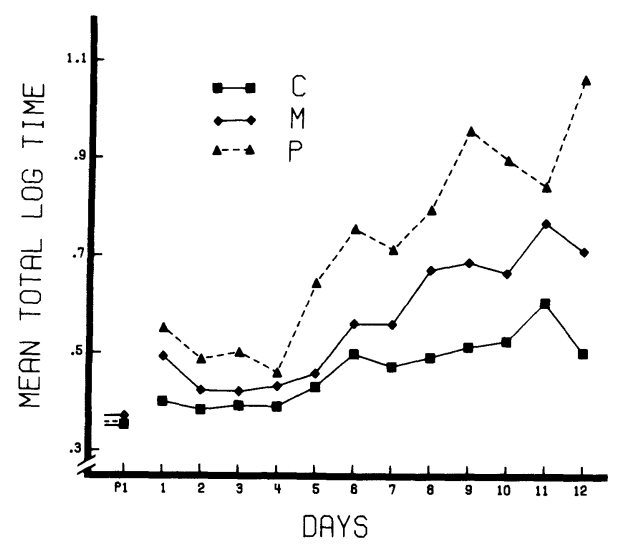

Figure 1. Mean total log time for each of the three groups on the last day of Phase 1 and each day of satiated testing.

to satiation was greatest for Group C, while Group M performed at an intermediate level.

The increase in running times between the first trial of the last day of Phase 1 and the first trial of Phase 2 was significant $[F(1,24)=13.99]$. The first trial of Phase 2 was used because subsequent trials confound the effect of shifting drive conditions with the effect of receiving reward while satiated. In this analysis, neither the main effect of groups nor the Groups by Trials interaction was significant $[\operatorname{Fs}(2,24)=1.99$ and 3.12 , ps $>.15$ and .05 , respectively] .

Over all of Phase 2, the difference associated with groups was significant $[\mathrm{F}(2,24)=3.81]$, as was the effect of days $[F(11,264)=9.15]$, reflecting the increase in running times over satiated testing. NewmanKeuls tests indicated that during the satiated test phase, Group P ran significantly slower than Group C, while no other individual group comparisons were significant. Note that although groups differed in running times in Phase 2 , the increase in running times during satiated testing did not differ between groups; that is, the Days by Groups interaction was not significant $[F(22,264)=1.14, p>.3]$. However, inspection of Figure 1 suggests that the increase in running times over Phase 2 was greatest for Group P, and when only the performance of Groups $\mathrm{P}$ and $\mathrm{C}$ during Phase 2 were analyzed together, the Days by Groups interaction was significant, even when the error term from the analysis of all three groups was used $[F(11,176)=2.07]$. Also, while groups did not differ significantly on Day 1 of Phase $2[F(2,24)=2.40, p>.1]$, they did differ on Day 12 of Phase $2[F(2,24)=4.48]$.

\section{Food Consumption in the Alley}

Figure 2 shows the mean number of pellets eaten per trial on each day of Phase 2. As Figure 2 indicates, food consumption declined rapidly over days for Group $\mathbf{P}$ and declined more slowly for Group $\mathrm{M}$. The mean number of pellets eaten by Group $\mathrm{C}$ showed no indication of decreasing even after 12 days of satiated testing. Analysis 


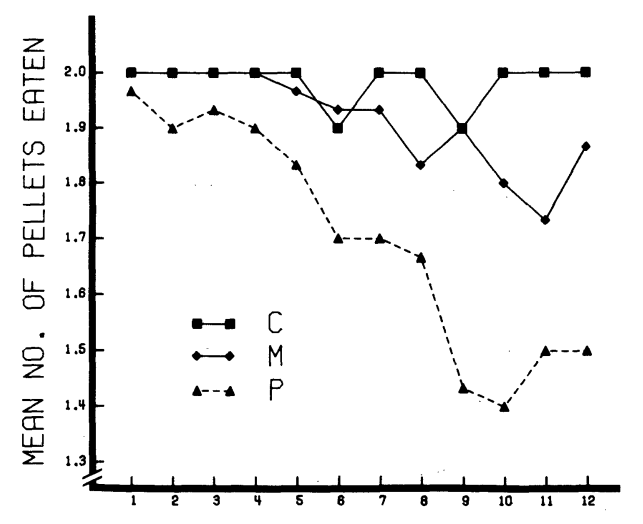

DAYS

Figure 2. Mean number of pellets eaten in the alley by each of the three groups on each day of satiated testing.

of variance over the number of pellets eaten during Phase 2 supported these observations, in that the effect of days was significant $[F(11,264)=4.10]$, as was the interaction of Days by Groups $[\mathrm{F}(22,264)=1.59]$. Newman-Keuls tests on each day of Phase 2 indicated that Group P ate fewer pellets than Group C on Days $9-12$ and fewer than Group M on Days 9, 10, and 12. The mean number of pellets eaten per trial for Groups $\mathrm{P}, \mathrm{M}$, and $\mathrm{C}$, respectively, was $1.70,1.91$, and 1.98. An analysis was also made over the frequency of trials during Phase 2 on which any eating occurred. Although frequency of eating decreased over days $[F(11,264)=3.02]$, it did not decrease differentially for the three groups $[\mathrm{F}(22,264)=1.23, \mathrm{p}>.2]$, nor was the main effect of groups significant $[\mathrm{F}(2,24)=2.57$, $\mathrm{p}>.05]$.

\section{Food Consumption in the Home Cage}

The mean amount of wet mash eaten each day of Phase 2 by Group $M$ ranged from $52.0 \mathrm{~g}$ to $64.2 \mathrm{~g}$ and averaged $59.3 \mathrm{~g}$ over all of Phase 2 . Of the $24 \mathrm{~g}$ of $.045 \mathrm{-g}$ Noyes pellets given to Group P each day of Phase 2, the mean amount eaten ranged from $15.1 \mathrm{~g}$ to $22.7 \mathrm{~g}$ and averaged $18.6 \mathrm{~g}$ over the entire satiated test phase. This means that on the average, each rat in Group $P$ consumed over 400 pellets each day. Also, a withinsubjects analysis of home-cage pellet consumption by Group $P$ revealed a significant change over days $[F(11,99)=5.80]$, and a subsequent trend analysis showed this to be due primarily to a linear decrease in pellet consumption over days $[F(1,99)=35.09]$.

\section{Body Weights}

An analysis of variance over body weights during Phase 2 satiated test days indicated that while all groups increased in body weights over days $[F(11,264)=91.24]$, there was no difference in weight between groups $[F(2,24)=1.09, \mathrm{p}>.35]$.

\section{DISCUSSION}

It is evident from these results that resistance to satiation in the alley varies as a function of the type of food that animals are given in their home cages. Group $P$ ran significantly slower than Group C and ate fewer pellets in the alley than the other groups. Group $\mathrm{C}$, in contrast, showed only a minimal increase in running times and ate the entire reward on nearly every trial. While Group $M$ performed at an intermediate level on both measures, it was never significantly different from Group C, so it will not be mentioned further.

We have suggested previously that resistance to satiation is produced by cues present in testing eliciting eating and running (Capaldi \& Myers, 1978). We have also suggested that one of the important cues eliciting eating and running is that produced by the memory of the number of pellets consumed on the previous trial (for data supporting this idea, see Capaldi \& Myers, 1978). These ideas provide an explanation of the present results. Group $P$ ate fewer pellets in the alley during satiated testing than Groups $M$ and $C$, and fewer pellets than all groups ate in acquisition. Thus the cue produced by number of pellets eaten on the previous trial was changed from that conditioned in acquisition for Group P more than for the other groups. On the basis of stimulus generalization decrement, Group P should have been less resistant to satiation of running than Groups $\mathrm{C}$ and $\mathrm{M}$, as it was.

Group $P$ showed a reduced tendency to eat pellets in the home cage. This result could indicate that to some extent, satiation is specific to particular foods, so that satiating an animal on pellets produces less eating of pellets than satiation on other foods. Or it could be that the animal must learn that eating is nonrewarding when satiated and that this learning is specific to the commodity consumed. So Group P would have learned that eating pellets is nonrewarding when satiated and this learning could generalize to the alley. The other groups would not have learned that eating pellets is nonrewarding until they experienced them in the alley.

In any case, the present results indicate that resistance to satiation is affected by the type of food used to satiate the animal, a finding difficult to explain within any model of resistance to satiation based on a general hunger drive or general food incentive, such as incomplete satiation, conditioned hunger, or a conditioned incentive. Rather, some process specific to the food consumed must be postulated within any theory of resistance to satiation, for example, pellet satiation, extinction of conditioned eating of pellets, extinction of the incentive value of pellets, and so on.

\section{REFERENCES}

BLACK, P. E., \& BLACK, R. W. Interaction of drive and incentive motivation, Psychonomic Science, 1967, 8, 129-130.

Black, R. V., \& Cox, M. Extinction of an instrumental running response in rats in the absence of frustration and nonreinforcement. Psychological Record, 1973, 23, 101-109.

Bolles, R. C. Theory of motivation (2nd ed.). New York: Harper \& Row, 1975.

Capaldi, E. D., \& Myers, D. E. Resistance to satiation of consummatory and instrumental performance. Learning and Motivation, 1978, 9, 179-201.

Cox, W. M. Eight drive-reward combinations: A test of incentive motivational theory. Bulletin of the Psychonomic Society, 1976, 7, 121-124.

GragG, L., \& Black, R. W. Runway performance following shifts in drive and reward magnitude. Psychonomic Science, 1967, 8, 177-178.

HaAs, R. R., Shessel, F. M., Willner, H. S., \& Rescorla, 
R. A. The effect of satiation following partial reinforcement. Psychonomic Science, 1970, 18, 296-297.

Lin'on, H. B., \& Miller, N. E. The effect of partial reinforcement on behavior during satiation. Journal of Comparative and Physiological Psychology, 1951, 44, 142-148.

Pencer, E. L. Persistence in the absence of primary motivation in the albino rat. Journal of Comparative and Physiological Psychology, 1974, 87, 787-792.

Wrinstock, R. B. Maintenance schedules and hunger drive: An examination of the rat literature. Psychological Bulletin, 1972, 78, 311-320.

Wong, P. T. P., \& Traupmann, K. L. Residual effects of food deprivation on food consumption and runway performance in the satiated rat. Journal of Comparative and Physiological Psychology, 1973, 84, 345-352. (a)

Wong, P. T. P., \& Traupmann, K. L. Sex differences and residual effects of food deprivation in the satiated rat. Canadian Journal of Psychology, 1973, 27, 422-427. (b)

Wong, P. T. P., \& Traupmann, K. L. Residual drive effects and stimulus control of eating. Psychological Reports, 1975 , 37, 31-38.

\section{NOTE}

1. Reciprocal transformations were employed in the previous study of resistance to satiation conducted in our laboratory (Capaldi \& Myers, 1978). Reciprocal transformations emphasize differences between short raw running times and deemphasize differences between long raw running times, which are often encountered with satiated animals. Logarithmic transformations were used in the present study because they were considered to treat differences between short raw running times and differences between long raw running times more equally. Reanalysis of the data of Capaldi and Myers (1978) using the logarithmic transformations yielded no changes in the results.

(Received for publication April 11, 1979.) 